\title{
Thermal mass and thermal comfort in offices - experimental studies of a concrete floor
}

\author{
Steinar Grynning ${ }^{1, *}$, Alessandro Nocente ${ }^{1}$, Lars Gullbrekken ${ }^{1}$, and Kjell Skjeggerud ${ }^{2}$ \\ ${ }^{1}$ SINTEF Building and Infrastructure, Department of Architecture, Building materials and \\ Construction, Høgskoleringen 7b, 7491 Trondheim, Norway \\ ${ }^{2}$ HeidelbergCement Norway, Lilleakerveien 2A, 0216 Oslo, Norway
}

\begin{abstract}
Previous studies demonstrated that the use of thermal mass in buildings can contribute to reduce the energy demand and improve the thermal comfort. The thermal mass effect strongly depends on the properties of the materials facing the internal environment. High thermal capacity and conductivity are vital to achieve the desired effects. Concrete have both and it is a common building material. However, scientifically sound experimental studies that quantify the effects in a controlled environment are scarce. The aim is to study the effects of thermal mass on indoor environment and comfort in a quantifiable way in an extensive experimental campaign where comparative measurements were carried out in The ZEB TestCell Laboratory in Trondheim, Norway. The facility consists of two identical real-weather exposed rooms the size of a single person office. One of the rooms was constructed with a $70 \mathrm{~mm}$ thick concrete flooring, the other with an $18 \mathrm{~mm}$ wood-flooring. Free-floating temperature propagations were measured in different natural ventilation scenarios. The results showed that peak temperatures were notably reduced in the test room with the concrete flooring. During the warmest periods, a temperature peak reduction of more than $10 \%$ was found compared to the wooden-floored room.
\end{abstract}

\section{Introduction}

In order to fulfil the goals of the Paris agreement, buildings of the future will be met by stricter and stricter demands for energy reductions. However, it is important that an improved energy performance does not compromise the comfort of buildings. A mayor driver for innovation and progress in the building sector is driven by governmental or international regulations. The Norwegian building regulations, it is assumed that measures to reduce local cooling demands are taken to meet the energy regulations [1]. Introducing thermal mass in a building as such a measure are much discussed. The thermal mass of a building determines its ability to store heat energy, as either sensible or latent heat, and this in turn can have a large influence over indoor temperatures, power requirements and occupant comfort [2].Thermal mass will increase the building's inertia making it possible to reduce peak temperatures during the warmer periods of the day. The building can become

* Corresponding author: steinar.grynning@sintef.no 
less responsive to sudden changes of outdoor temperature. If designed properly, a coordinated use of the thermal mass and the energy systems can make it possible to store and release thermal energy in a diurnal or slightly longer cycle. This is in line with the conclusions from Høseggen [3], who state that the main advantages of thermal mass are smaller temperature amplitudes during the day and thus a more comfortable indoor climate.

The thermal mass activation depends on several factors. Material properties such as thermal conductivity of the exposed layer and the specific heat capacity [2] determine the thermal diffusivity of the concrete (i.e the speed of which thermal energy are being absorbed and released in the concrete). Heavy materials (like concrete) will thus be able to absorb a large part of energy from solar radiation and even out temperature oscillations in the room [2].

The effect of thermal mass on the behaviour of a building is a complex phenomenon being dependent on the material-related properties, climatic conditions and the resulting heat gains, losses and storage in the building materials and finishing. Although this phenomenon have been studies extensively [4], the number of experimental campaigns aimed at describing these phenomena using comparative monitoring campaigns are scarce [5]. According to a paper from 2008 [6], two such campaigns had been carried out [7], [8]. This is confirmed by [5] in 2018 which points to the same studies. Is addition to these, a study from 1998 [9] have been identified. Here, measurements from three test buildings were presented. It was found that the peak temperature of the test building with a heavy concrete exterior- and partitioning walls were lowered by more than $3^{\circ} \mathrm{C}$ compared to a lightweight building during a warm spell (outdoor temperature of $35^{\circ} \mathrm{C}$ ). The effects of using a concrete floor as thermal mass is not studied. Additionally, these studies present results from buildings with poorly insulated structures and the need for scientifically sound, high-quality comparative experiments relevant for today's building standards are imminent.

This paper presents the results of the first phase of an extensive experimental campaign aimed at quantification of the effects of a thermal mass on the internal thermal conditions of a single person office cubicles. Further studies are planned on investigating the effects on the energy demand for maintaining a comfortable thermal climate in the test cells.

\section{Test Facility}

\subsection{The ZEB Test Cell Laboratory}

The measurements were carried out in the ZEB Test Cell Laboratory at the Norwegian University of science and Technology (NTNU) in Trondheim, Norway [10]. The facility (Fig. 1) is constituted of two identical rooms with dimensions of a typical single office space: (W x L x H): $2.4 \mathrm{~m} \times 4.2 \mathrm{~m} \times 3.3 \mathrm{~m}$. Each test room is suspended in a guard space and can exchange heat only through the facade. The facade includes a window with dimensions $(\mathrm{W} \times \mathrm{H}) 2.02 \mathrm{~m} \times 2.09 \mathrm{~m}$ facing South. The specifications of the facades are summarized in Table 1. The solar heat gain coefficient (g-value) of the glazing unit is 0.38 and the visible light transmittance $\left(\mathrm{T}_{\text {vis }}\right)$ is 0.59 . The remaining part of the façade is a wood-frame construction with an insulation thickness of $250 \mathrm{~mm}$. The walls, ceiling and floor of each test cell facing the surrounding guard-room are made of prefabricated sandwich panels $(0.6$ $\mathrm{mm}$ stainless steel sheets and $10 \mathrm{~cm}$ thick injected-polyurethane foam) with a U-value of $0.23 \mathrm{~W} / \mathrm{m} 2 \mathrm{~K}$. The cell is suspended from the floor of the main building, leaving an air gap of approximately $0.5 \mathrm{~m}$ under the cell. 


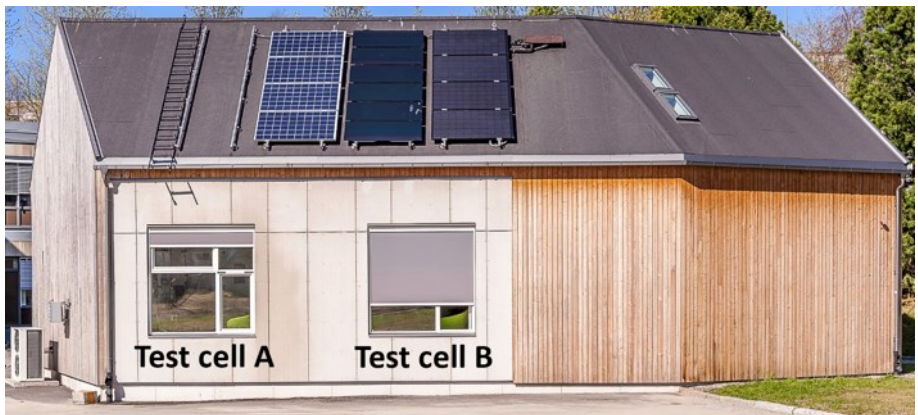

Fig. 1. The ZEB Test Cell laboratory, view of the southern façade

Table 1. Specification of the test cell facade.

\begin{tabular}{|l|c|c|}
\hline Façade part & Area & U-value \\
\hline Whole window (27\% frame fraction) & $4.2 \mathrm{~m}^{2}$ & $0.84 \mathrm{~W} /\left(\mathrm{m}^{2} \mathrm{~K}\right)$ \\
Glazing units & $3.1 \mathrm{~m}^{2}$ & $0.62 \mathrm{~W} /(\mathrm{m} 2 \mathrm{~K})$ \\
\hline Opaque façade area & $3,7 \mathrm{~m}^{2}$ & $0.20 \mathrm{~W} /\left(\mathrm{m}^{2} \mathrm{~K}\right)$ \\
\hline
\end{tabular}

The two test cells and the two guard rooms have independent HVAC systems. The experimental facility is originally designed for testing building envelope systems against outdoor conditions either in comparative or calorimetric tests. Anyway, the large number of sensors, the redundant equipment, and the flexibility in hardware and control system makes it an ideal environment for testing the interaction between HVAC system, building envelope and building component in general.

\subsection{Instrumentation}

For the experiment presented in this work, a $70 \mathrm{~mm}$ thick floor was constructed with concrete tiles, each of dimension circa $700 \mathrm{~mm} \times 800 \mathrm{~mm}$, while the other cell was equipped with an $18 \mathrm{~mm}$ tick wooden floor (Fig. 2). The surface temperatures in the room are recorded by 15 T-type thermocouples placed on the ceiling, and the East, West and North walls. 4 thermocouples are placed on the glazed surface of the window while two of the tiles are instrumented with thermocouples on the upper and lower surfaces. The radiant temperature is measured by a black globe thermometer suspended in the centre of the room, at a height of $1.5 \mathrm{~m}$ with a distance of $2.4 \mathrm{~m}$ from the window. Air temperature is measured by means of 5 Pt100 thermometers. These are placed on two masts, one at the centre of the room, the other at one corner $600 \mathrm{~mm}$ from the walls. The central mast is equipped with three Pt100 thermometers respectively placed at 100, 600 and $1100 \mathrm{~mm}$ from the floor, while the corner mast holds $2 \mathrm{Pt100}$ at 600 and $1100 \mathrm{~mm}$ from the floor. The temperature difference between the upper and the lower part of the concrete floor is measured by mean of two pairs of type $\mathrm{T}$ thermocouples in two points along the central axis of the room at distance of respectively $1.4 \mathrm{~m}$ and $2.8 \mathrm{~m}$ from the window. Heating and cooling is carried out respectively by a radiator and a fan-coil. Thermal energy flow through the water lines is measured on each of the four circuits by a Kamstrup Multical602 energy meter. On the facility roof is mounted a weather station that continuously logs all weather parameters.

The rooms are illuminated by neon tubes for a total power of $180 \mathrm{~W}$ each cell. To simulate the office occupant, a $100 \mathrm{~W}$ mannequin is used. Both mannequin and lights are controlled by the main computer with an on-off based schedule, from 8:00am to 4:00pm in weekdays, off during the weekends. All sensors, power sockets consumption, controllers' 
activities and machines (i.e. water pumps) are continuously logged with a sample time of 60 seconds. Heating and cooling systems are controlled according to the internal air temperature. The radiator is active in the temperature band between $21^{\circ} \mathrm{C}$ and $23^{\circ} \mathrm{C}$, while the fan coil between $24^{\circ} \mathrm{C}$ and $26^{\circ} \mathrm{C}$.

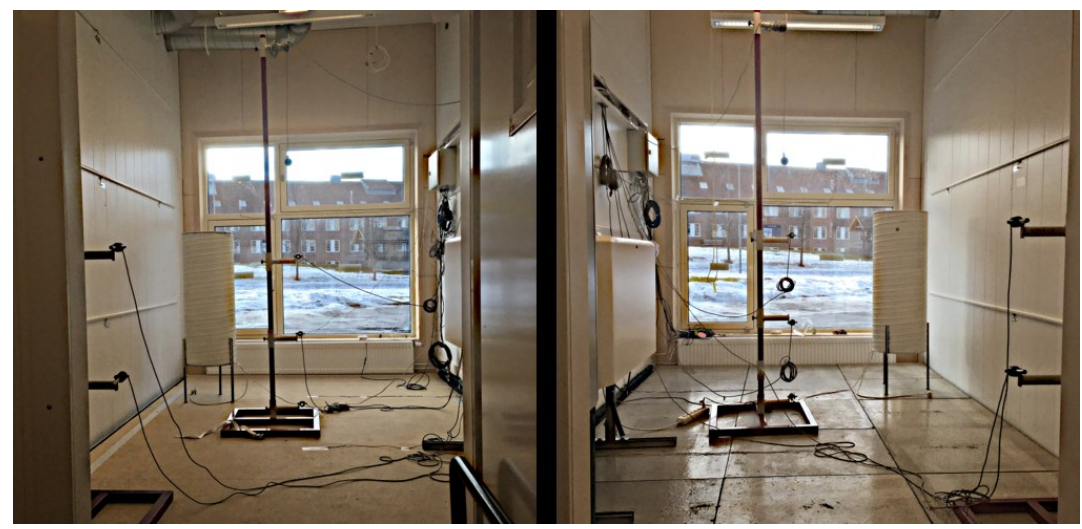

Fig. 2. View of the test cells: Cell A (left) constructed with wooden floor, Cell B (right) constructed with concrete floor

\subsection{Test procedure}

For this test the ventilation ducts of the rooms were sealed, the windows kept closed, and no solar screen was used. Data logging started 2 days after sealing the cell doors, to give enough time for the concrete floor to stabilise its temperature. The data were acquired from June $22^{\text {nd }}$ to July $4^{\text {th }}$. During this period the outdoor temperature varied in a range of roughly $18^{\circ} \mathrm{C}$. All data were logged with every 60 seconds.

\section{Results}

The measured globe temperatures of each test room and the outdoor temperature are reported in Fig. 3 for the whole duration of the experiment. As mentioned, the outdoor temperature had a wide variation during the time of interest. The blue curve indicates the radiant (operative) temperature registered in cell $\mathrm{A}$ (wooden floor), while the red curve represents the radiant temperature in cell B (concrete floor). The diagram shows how the indoor temperature variation in case of concrete floor is reduced over the whole investigation period. The daily temperature peaks in sunny days show that the temperature in cell B is up to $10 \%$ inferior of the temperature in cell A. During the night, in the same days, the temperature in cell B is slightly higher. During a colder period, between June $28^{\text {th }}$ and June $30^{\text {th }}$ where low solar radiation entered the rooms, daily peaks are negligible. Nevertheless, it is evident how the cell equipped with concrete mass registers a higher temperature, also here the difference is quantifiable in circa $10 \%$. Measured temperatures above and below the concrete tiles are shown in Fig. 4. One can see that the peak temperature below Tile 1 (closed to the window) is approximately $5 \mathrm{C}$ higher than that of Tile 2 (in the back of the room). This suggest that a substantial part of the thermal mass of the concrete tiles directly affected by solar radiation have been activated. Following this, it can be argued that an even larger amount of thermal mass could have been utilized in the room. 


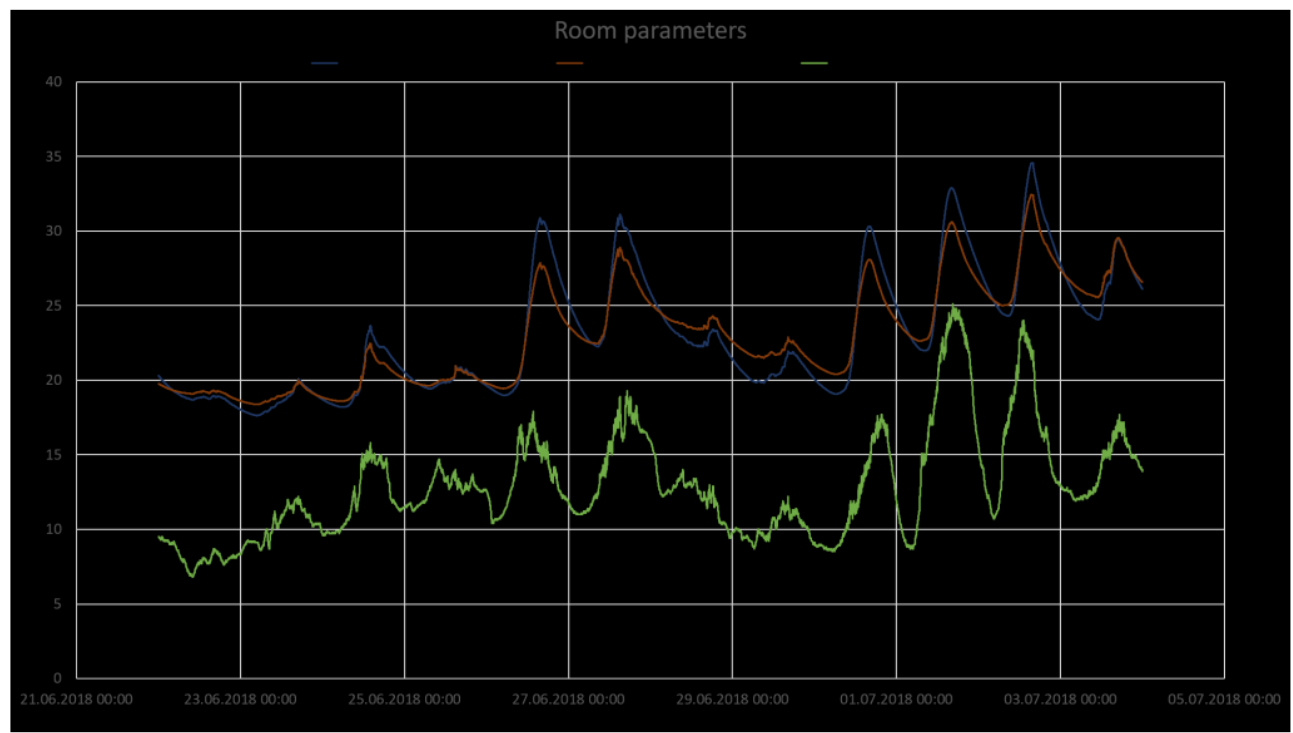

Fig. 3. Black globe temperature in the test cells and outside temperature during the whole duration of the measurements

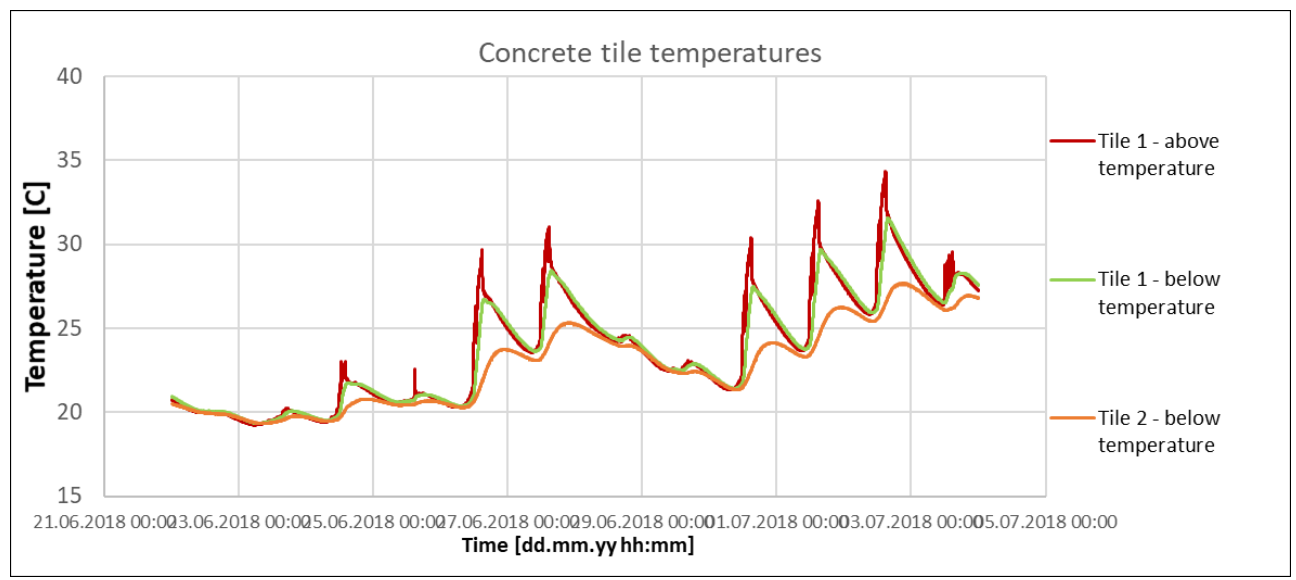

Fig. 4. Measured surface temperatures above and below concrete tiles.

\section{Conclusions}

We have carried out measurements on how an exposed concrete flooring influence the temperature levels in a large-scale laboratory test facility. These measurements were compared to measurements in an identical (and adjacent) test room with a wooden particleboard flooring. The rooms were set up to mimic office cubicles. The registered data showed that the introduction of thermal mass, in the form of concrete tiles, in one of the test cells gave a significant impact on the temperature propagation in the room. Compared to the cell with a wooden flooring, higher peak temperatures in the considered period were reduced by an average of $7 \%\left(2.5^{\circ} \mathrm{C}\right)$ up to $10 \%$. Lower peak temperatures were increased by $1.5 \%$ on average. This leads to a more comfortable temperature levels for potential users of such rooms. Additionally, it can help to reduce cooling demands during warm periods in office cubicles like this. Furthermore, it was found that the thermal mass capabilities of a $7 \mathrm{~cm}$ 
thick concrete flooring can be activated for the measured climatic conditions and that an even larger effect on reducing peak temperature could have been achieved using a thicker layer of concrete. Further studies aim at studying how thermal mass influence the heating and cooling demands to keep the temperature levels within a set boundary to maintain a good thermal comfort. Additionally, the measurements will be used for calibration of a simulation model with an aim to upscale the measurements for use on whole buildings.

The authors gratefully acknowledge the support from the Research Council of Norway and several partners through the Research Centre on Zero Emission Neighbourhoods in Smart Cities (FME ZEN) under grant No. 257660. This paper is also supported by the SkinTech project funded by the Research Council of Norway under grant No. 255252 and the industrial partners in the project.

\section{References}

[1] K.-O. REGIONALDEPARTEMENTET, "BYGGTEKNISK FORSKRIFT (TEK17)," LOVDATA, JUN, 2017.

[2] M. J. Alonso and H. M. Mathisen, "Analysis of reduction of energy demands for Zero Emission Renovated Office Building by using thermal mass and ventilative cooling," Energy Procedia, vol. 132, pp. 592-597, 2017.

[3] R. Z. Høseggen, "Dynamic use of the building structure-energy performance and thermal environment," 2008.

[4] S. Ø. Jensen et al., "IEA EBC Annex 67 Energy Flexible Buildings," Energy Build., vol. 155, no. 2017, pp. 25-34, 2017.

[5] S. Verbeke and A. Audenaert, "Thermal inertia in buildings: A review of impacts across climate and building use," Renew. Sustain. Energy Rev., vol. 82, pp. 23002318, 2018.

[6] T. Kalema, G. Jóhannesson, P. Pylsy, and P. Hagengran, “Accuracy of energy analysis of buildings: a comparison of a monthly energy balance method and simulation methods in calculating the energy consumption and the effect of thermal mass," J. Build. Phys., vol. 32, no. 2, pp. 101-130, 2008.

[7] T. Kalema and H. Martikainen, "The effect of buildings' structures and the heat distribution system on the heating energy of a single-family house (in Finnish)," 1987.

[8] R. Lindberg, A. Binamu, and M. Teikari, "Five-year data of measured weather, energy consumption, and time-dependent temperature variations within different exterior wall structures," Energy Build., vol. 36, no. 6, pp. 495-501, 2004.

[9] B. Givoni, "Effectiveness of mass and night ventilation in lowering the indoor daytime temperatures. Part I: 1993 experimental periods," Energy Build., vol. 28, no. 1, pp. 25-32, 1998.

[10] F. Goia, C. Schlemminger, and A. Gustavsen, "The ZEB Test Cell Laboratory. A facility for characterization of building envelope systems under real outdoor conditions," Energy Procedia, vol. 132, pp. 531-536, Oct. 2017. 